\title{
Toward a test of the "Law of Crime Concentration" in Japanese cities: a geographical crime analysis in Tokyo and Osaka
}

\author{
Mamoru Amemiya ${ }^{1^{*}}$ and Tomoya Ohyama²
}

\begin{abstract}
This brief report aims to reveal crime concentration at the district level in Tokyo and Osaka, Japan, two cities characterized by low crime rates. Eight types of property crimes that occurred between 2008 and 2017 in Tokyo and Osaka and had been aggregated by the census enumeration district were analyzed using the Gini coefficient based on the Poisson-Gamma method. The results indicated three patterns. First, crime concentration was identified. Second, the degree of concentration depended upon crime type. Commercial burglary was the most concentrated crime type, and theft from vehicle and theft from vending machine were the most dispersed. Third, crime concentration patterns either remained stable or became more concentrated over time. Additionally, while theft of bicycle was found to display stable concentration levels over time, the concentration level of purse snatching was fluid. On the basis of the results, this report discusses the possibility of establishing the "Law of Crime Concentration" (LCC) in two Japanese cities.
\end{abstract}

Keywords: Law of Crime Concentration, Gini coefficient, Property crime, Tokyo, Osaka, Japan

\section{Introduction}

The "Law of Crime Concentration" (LCC) is the wellknown phenomenon that many crimes are concentrated in specific small areas of a city regardless of city or year (Weisburd 2015). Since being established as a "law" in 2015, LCC has been tested in several cities (Table 1). However, no study has tested LCC's applicability to Asian cities with low crime (Lee et al. 2017). Testing LCC in a different social context constitutes a significant attempt to enhance the robustness and generalizability of LCC.

Tokyo and Osaka, both Asian cities with low crime, ${ }^{1}$ are the only two cities in Japan where long-time crime data have been open to the public. Although available crime data in both cities are aggregated by district level, overall crime concentration may be identified using the data. A district-level examination of crime concentration does not necessarily entail verification of LCC because the district is too large a spatial unit. However, the attempt is still important as it suggests the feasibility of LCC. As a first step toward testing LCC in Asian cities, this brief report describes crime concentration at district level in Tokyo and Osaka, focusing on the difference in the degree of crime concentration among crime types, and the stability of crime concentration by crime types over 10 years.

*Correspondence: amemiya@sk.tsukuba.ac.jp

${ }^{1}$ Division of Policy and Planning Sciences, Faculty of Engineering, Information and Systems, University of Tsukuba, 1-1-1 Tennodai,

Tsukuba-shi, Ibaraki 305-8573, Japan

Full list of author information is available at the end of the article

\footnotetext{
${ }^{1}$ Although the intercity international comparison of property crimes is generally difficult because of the difference in the definition of crime types among countries, according to some recent international comparisons, the overall safety from crime in Asian cities tends to be high, with Tokyo and Osaka being two of the safest cities among them (The Economist Intelligence Unit 2017; NUMBEO 2019).
} 
Table 1 List of previous studies that tested LCC after 2015

\begin{tabular}{|c|c|c|}
\hline Countries & Cities & Sources \\
\hline US & Boston & O'Brien and Winship (2017); O'Brien (2019) \\
\hline US & Brooklyn Park & Gill et al. (2017) \\
\hline US & Chicago & Schnell et al. (2017) \\
\hline US & Philadelphia & Haberman et al. (2017) \\
\hline US & Seattle & Hibdon et al. (2017) \\
\hline US & St. Louis & Levin et al. (2017) \\
\hline US & 42 cities in southern California & Hipp and Kim (2017) \\
\hline Canada & Vancouver & Andresen et al. (2017a), (b) \\
\hline Belgium & Antwerp & Vandeviver and Steenbeek (2019) \\
\hline Belgium & Two anonymous cities & Hardyns et al. (2019) \\
\hline Netherlands & Hague & Steenbeek and Weisburd (2016) \\
\hline Italy & Milan & Favarin (2018) \\
\hline Brazil & Campinas & de Melo et al. (2015) \\
\hline South Africa & Khayelitsha & Breetzke and Edelstein (2018) \\
\hline
\end{tabular}

\section{Data and method \\ Data}

Tokyo's 23 wards and Osaka City, respectively referred to as "Tokyo" and "Osaka" in this paper, are the largest cities in Japan. The respective populations in 2017 were 8,892,312 and 2,566,593 (Statistics Bureau in Japan 2018). Since 2008, their respective prefectural police forces have provided crime data aggregated by crime type and census enumeration district for every month of every year. ${ }^{2}$ These open data schemes are the only two such schemes from any of the Japanese prefectures, and they together constitute the sole reason that Tokyo and Osaka were selected as sites for this study. The respective number of the census enumeration districts in Tokyo and Osaka are 3117 and 1904. Eight types of property crimes-residential burglary, commercial burglary, office burglary, theft from vehicle, theft of vehicle, theft of bicycle, purse snatching, and theft from vending machinethat occurred between 2008 and 2017 were analyzed. ${ }^{3}$ Reflecting the overall trend in Japan (Sidebottom et al. 2018), all crime types in both cities have decreased since 2008 (Fig. 1).

\section{Indicators of crime concentration}

Previous studies have generally measured crime concentration using either the ratio of number of spatial units that consist of $25 \%$ or $50 \%$ of all crimes in one city (e.g.,

\footnotetext{
${ }^{2}$ Data are available at https://www.bouhan.metro.tokyo.lg.jp/opendata/index .html (Tokyo) and https://www.police.pref.osaka.lg.jp/anmachi/index.html (Osaka). User registration is necessary in Osaka.

${ }^{3}$ Crime types reported in the available crime data differ between Tokyo and Osaka. Data for these eight property crimes are available in both cities.
}

Weisburd 2015), or the Gini coefficient (G) (e.g., Steenbeek and Weisburd 2016). Bernasco and Steenbeek (2017) propose the generalized Gini coefficient $\left(G^{\prime}\right)$ as an indicator of crime concentration in situations with fewer crimes than the number of spatial units since raw $G$ overestimates crime concentration when the number of crimes is smaller than the number of spatial units. However, all of these crime concentration indicators have recently been shown to overestimate or underestimate crime concentration (Mohler et al. 2019). In order to estimate crime concentration unbiasedly, Mohler et al. (2019) suggests using the Gini coefficient based on the Poisson-Gamma method ( $\hat{G})$ (Mohler et al. 2019). $\hat{G}$ can estimate crime concentration with reducing bias, particularly in the case that the number of crimes is much smaller than the number of spatial units (For the theoretical and mathematical background, see Mohler et al. (2019)).

This current study makes two analyses of crime concentration in Tokyo and Osaka using $\hat{\mathrm{G}}$. In the first analysis, differences in the degree of crime concentration among crime types are examined. After summing the yearly number of each crime type from 2008 to 2017 by census enumeration district for Tokyo and Osaka, $\hat{G}$ is calculated and compared among crime types in each city. In the second analysis, the stability of crime concentration by crime types over 10 years in each city was examined on the basis of $\hat{G}$.

\section{Spatial unit of analysis}

While it is necessary to use crime data aggregated by certain spatial units to calculate crime concentration indicators, previous studies used small spatial units 

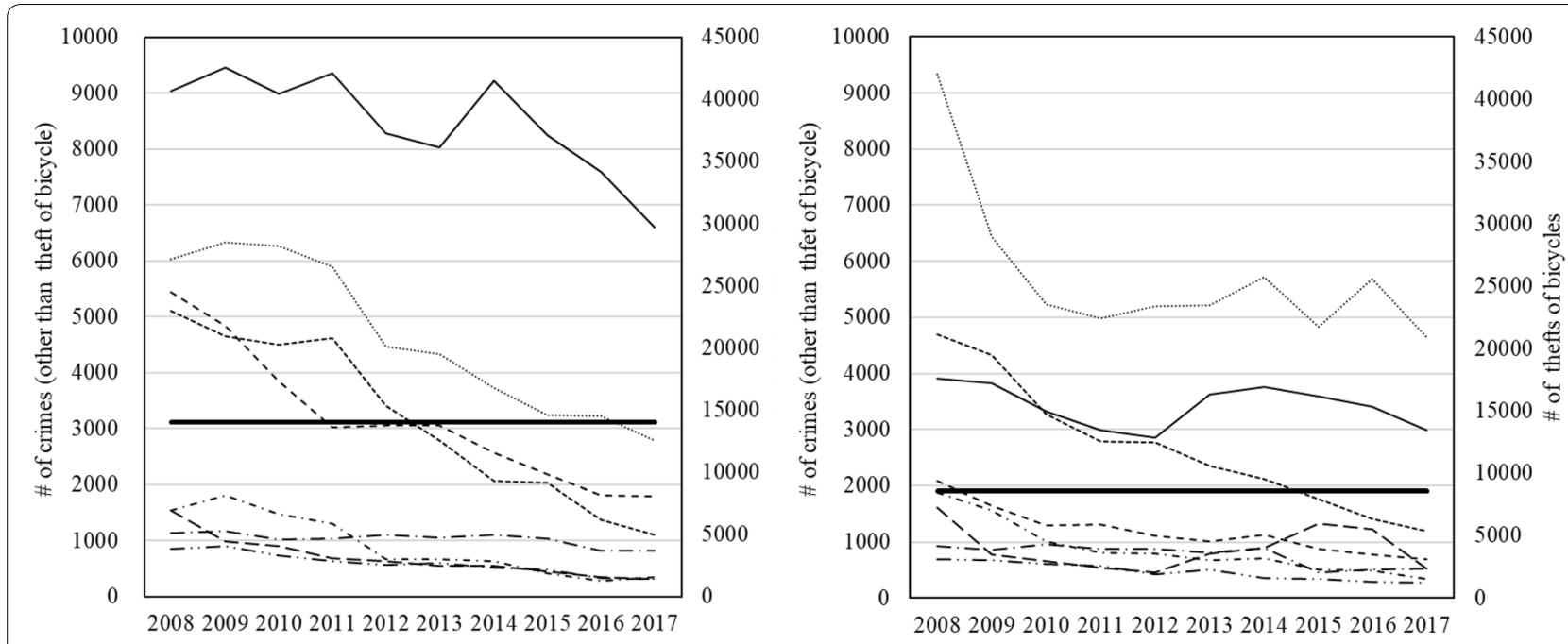

Key

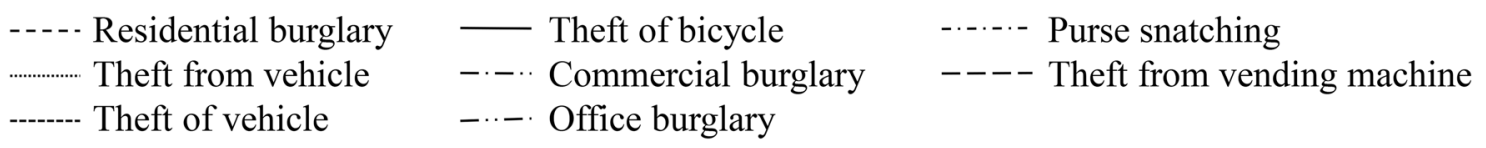

\# of spatial units (census enumeration districts) (left axis)

Fig. 1 Number of crimes in Tokyo (left) and Osaka (right) between 2008 and 2017

such as street segments or small-sized $(200 \mathrm{~m})$ grids (e.g., Hardyns et al. 2019; Weisburd 2015). However, the only available crime data for Tokyo and Osaka constitute data that have already been aggregated by respective census enumeration district, each with an average size $\left(0.195 \mathrm{~km}^{2}\right.$ in Tokyo and $0.116 \mathrm{~km}^{2}$ in Osaka) larger than the spatial units used by previous studies (e.g., Hardyns et al. 2019; Weisburd 2015). As a result, we cannot use spatially detailed crime data as used in previous studies. Because of this data limitation, this study uses the census enumeration district as a spatial unit of analysis. If larger spatial units are used to calculate G, estimated crime concentration tends to be weaker even in the same crime geographical distribution pattern (Schnell et al. 2017; Steenbeek and Weisburd 2016; O'Brien 2019). Therefore, $\hat{G}$ as calculated in this study by using the census enumeration district as a spatial unit of analysis will be smaller than $\hat{G}$ as calculated using smaller units such as street segments. This is the limitation of this report.

\section{Results}

Figure 2 shows $\hat{G}$ for each crime type. $\hat{G}$ values in Fig. 2 are calculated on the basis of the total number of crimes from 2008 to 2017. In both Tokyo and Osaka, G ranged between 0.40 and 0.63 . Whereas commercial burglary and office burglary featured a relatively high $\hat{G}$, the other crime types featured a low $\hat{G}$. Although $\hat{G}$ for all types of crime in Osaka were slightly smaller than for Tokyo, $\hat{\mathrm{G}}$ for each crime type in Tokyo and Osaka followed the same pattern $(r=0.908, p<0.001)$.

Figure 3 shows the annual $\hat{G}$ for each crime type. The annual changing patterns of $\hat{G}$ for all types of crime were either stable or modestly increased. The trends of $\hat{G}$ for all types of crime between Tokyo and Osaka were similar. This result implies that the concentration of each crime either remained unchanged or became stronger in both cities for the years between 2008 and 2017.

\section{Discussion and conclusion}

Recent studies analyzing crime concentration using spatial scale equal to or larger than that used in this study report G values of about 0.50 (Schnell et al. 2017; Steenbeek and Weisburd 2016). The $\hat{G}$ values identified by this study depended on crime type; however, they all fell between 0.40 and 0.70, as shown in Fig. 2. Although the $G$ values in these prior studies may be biased toward larger values (Mohler et al. 2019), a consideration of the similarities among the $\mathrm{G}$ values in this current study and 


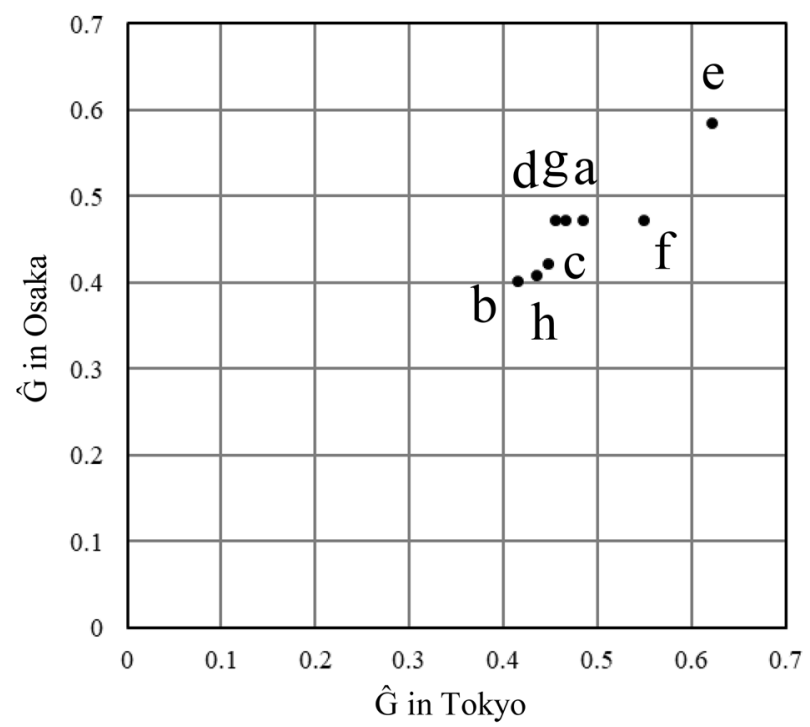

Key

a: Residential burglary

b: Theft from vehicle

c: Theft of vehicle

d: Theft of bicycle

e: Commercial burglary

f: Office burglary

g: Purse snatching

$\mathrm{h}$ : Theft from vending machine

Fig. 2 Gini coefficient for each crime type in Tokyo and Osaka calculated using the total number of crimes from 2008 to 2017

the $G$ values from the prior studies permits the conclusion that crime concentration is recognized in Tokyo and Osaka as well as other cities studied previously at least at the district level. However, since the research that verified LCC generally used smaller spatial units of analysis, it cannot be concluded that LCC was verified in Japan only from the results of this study. Rather, the results of this study should be considered as indicating a promising prospect for LCC validation.

Because of the limitations of data, the results of this study cannot be directly and numerically compared with previous studies using smaller spatial units of analysis. However, the results of this study are partially consistent with previous studies at a more general level. First, commercial burglary, featuring disproportionately distributed potential targets, was the most concentrated crime type, whereas theft from vehicle and theft of vehicle were the most dispersed crime types. Concentration of commercial burglary and dispersion of theft from/of vehicle were consistent with the results of a study conducted in Vancouver (Andresen et al. 2017a, b). Second, while total crime decreased, the respective concentrations of each crime type were either unchanged or strengthened. This result is consistent with the findings of previous studies that crime concentration stayed static in situations of crime decrease (Hardyns et al. 2019; Vandeviver and Steenbeek 2019). These facts imply that the nature of crime concentration in Tokyo and Osaka is partially consistent with that in cities outside Japan, at least at the district level. Practically, the results of this report indicate that "hotspot policing", the effectiveness of which has been demonstrated in other countries (Braga et al. 2014), can be effective in Japanese cities as well.

Analyzing more spatially detailed crime data and obtaining stricter verification of LCC are future challenges. Previous studies have found that analysis using smaller spatial units tends to find stronger crime concentrations (Schnell et al. 2017; Steenbeek and Weisburd 2016; O'Brien 2019). Thus, if more detailed data can be analyzed in the future, a more robust basis for establishing LCC can be presented. Another challenge lies in identifying the factors of crime concentration, including population distribution or the socio-demographic backgrounds of cities. Despite these limitations, this study is the first attempt to discuss the feasibility of LCC in Asian cities and is significant as a foundation toward further research for enhancing the generalization of LCC. 


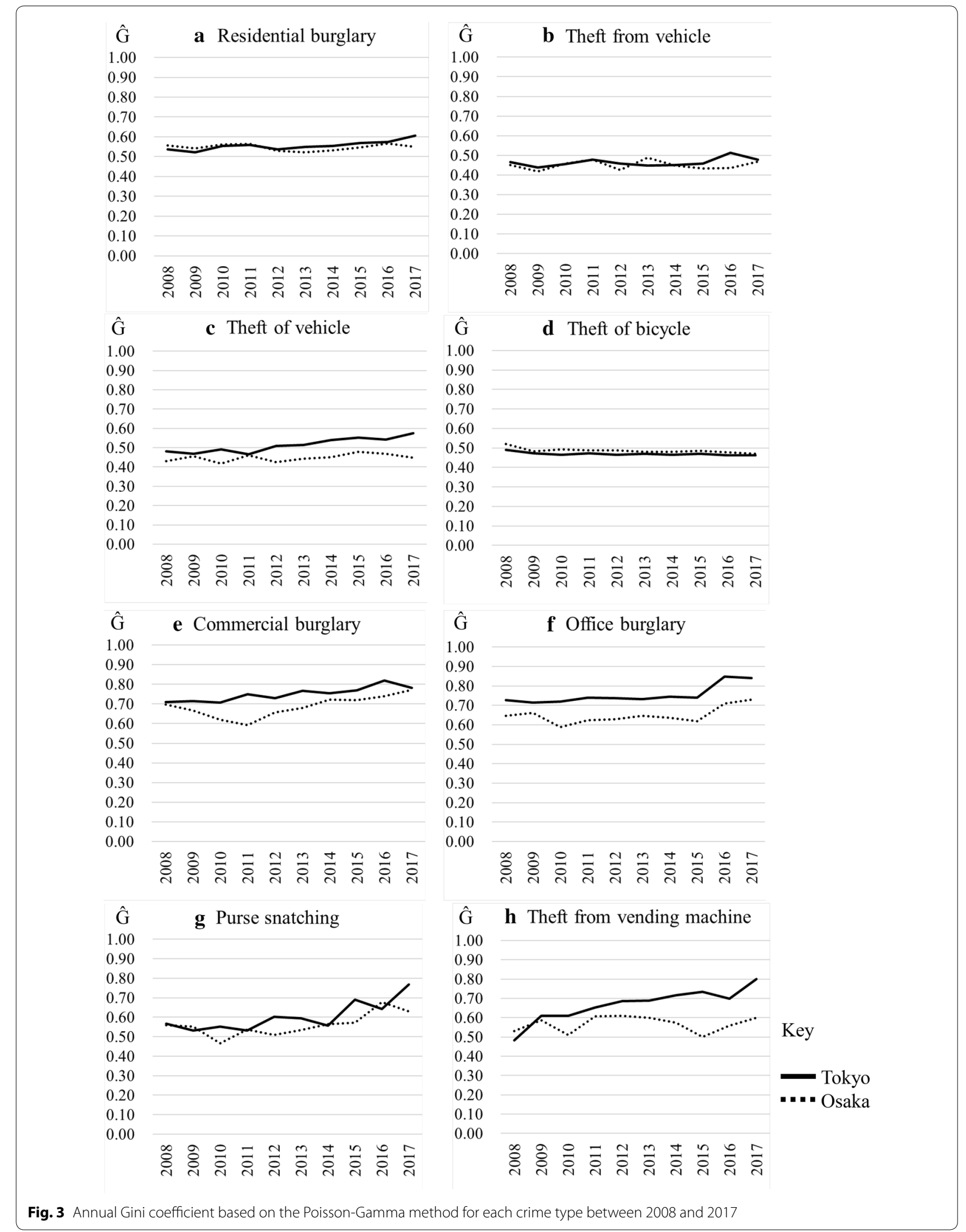




\section{Abbreviations}

LCC: Law of Crime Concentration; G: Gini coefficient; G': Generalized Gini coefficient; $\hat{G}$ : Gini coefficient based on the Poisson-Gamma method.

\section{Acknowledgements}

Not applicable.

\section{Authors' contributions}

MA analyzed and interpreted the crime data and wrote the first draft of the manuscript. TO advised on the analysis and interpretation of results and contributed to manuscript revision. Both authors read and approved the final manuscript.

\section{Authors' information}

MA is Associate Professor of the Division of Policy and Planning Sciences, Faculty of Engineering, Information and Systems, University of Tsukuba. TO is a doctoral student in the Policy and Planning Sciences program at the Graduate School of Systems and Information Engineering, University of Tsukuba.

\section{Funding}

This work was supported by MEXT KAKENHI Grant Number $17 \mathrm{H} 02046$.

\section{Availability of data and materials}

Data are available at http://www.bouhan.metro.tokyo.jp/opendata/index.html (Tokyo) and https://www.police.pref.osaka.lg.jp/anmachi/index.html (Osaka). User registration is necessary in Osaka.

\section{Competing interests}

The authors declare that they have no competing interests.

\section{Author details}

${ }^{1}$ Division of Policy and Planning Sciences, Faculty of Engineering, Information and Systems, University of Tsukuba, 1-1-1 Tennodai, Tsukuba-shi, Ibaraki 305-8573, Japan. ${ }^{2}$ Department of Policy and Planning Sciences, Graduate School of Systems and Information Engineering, University of Tsukuba, 1-1-1 Tennodai, Tsukuba-shi, Ibaraki 305-8573, Japan.

Received: 13 April 2019 Accepted: 27 September 2019 Published online: 13 October 2019

\section{References}

Andresen, M. A., Curman, A. S., \& Linning, S. J. (2017a). The trajectories of crime at places: Understanding the patterns of disaggregated crime types. Journal of Quantitative Criminology, 33(3), 427-449. https://doi.org/10.1007/ s10940-016-9301-1.

Andresen, M. A., Linning, S. J., \& Malleson, N. (2017b). Crime at places and spatial concentrations: Exploring the spatial stability of property crime in Vancouver BC, 2003-2013. Journal of Quantitative Criminology, 33(2), 255-275. https://doi.org/10.1007/s10940-016-9295-8.

Bernasco, W., \& Steenbeek, W. (2017). More places than crimes: Implications for evaluating the Law of Crime Concentration at place. Journal of Quantitative Criminology, 33(3), 451-467. https://doi.org/10.1007/s1094 0-016-9324-7.

Braga, A. A., Papachristos, A. V., \& Hureau, D. M. (2014). The effects of hot spots policing on crime: An updated systematic review and metaanalysis. Justice Quarterly, 31(4), 633-663. https://doi.org/10.1080/07418 825.2012.673632.

Breetzke, G. D., \& Edelstein, I. S. (2018). The spatial concentration and stability of crime in a South African township. Security Journal, 32(1), 63-78. https ://doi.org/10.1057/s41284-018-0145-2.

de Melo, S. N., Matias, L. F., \& Andresen, M. A. (2015). Crime concentrations and similarities in spatial crime patterns in a Brazilian context. Applied Geography, 62, 314-324. https://doi.org/10.1016/j.apgeog.2015.05.012.

Favarin, S. (2018). This must be the place (to commit a crime). Testing the Law of Crime Concentration in Milan, Italy. European Journal of Criminology, 15(6), 702-729. https://doi.org/10.1177/1477370818757700.
Gill, C., Wooditch, A., \& Weisburd, D. (2017). Testing the "Law of Crime Concentration at place" in a suburban setting: Implications for research and practice. Journal of Quantitative Criminology, 33(3), 519-545. https://doi. org/10.1007/s10940-016-9304-y.

Haberman, C. P., Sorg, E. T., \& Ratcliffe, J. H. (2017). Assessing the validity of the Law of Crime Concentration across different temporal scales. Journal of Quantitative Criminology, 33(3), 547-567. https://doi.org/10.1007/s1094 0-016-9327-4.

Hardyns, W., Snaphaan, T., \& Pauwels, L. J. (2019). Crime concentrations and micro places: An empirical test of the "Law of Crime Concentration at places" in Belgium. Australian \& New Zealand Journal of Criminology, 52(3), 390-410. https://doi.org/10.1177/0004865818807243.

Hibdon, J., Telep, C. W., \& Groff, E. R. (2017). The concentration and stability of drug activity in Seattle, Washington using police and emergency medical services data. Journal of Quantitative Criminology, 33(3), 497-517. https:// doi.org/10.1007/s10940-016-9302-0.

Hipp, J. R., \& Kim, Y. A. (2017). Measuring crime concentration across cities of varying sizes: Complications based on the spatial and temporal scale employed. Journal of Quantitative Criminology, 33(3), 595-632. https://doi. org/10.1007/s10940-016-9328-3.

Lee, Y., Eck, J. E., SooHyun, O., \& Martinez, N. N. (2017). How concentrated is crime at places? A systematic review from 1970 to 2015. Crime Science, 6, 6-21. https://doi.org/10.1186/s40163-017-0069-x.

Levin, A., Rosenfeld, R., \& Deckard, M. (2017). The Law of Crime Concentration: An application and recommendations for future research. Journal of Quantitative Criminology, 33(3), 635-647. https://doi.org/10.1007/s1094 0-016-9332-7.

Mohler, G., Brantingham, P. J., Carter, J., \& Short, M. B. (2019). Reducing bias in estimates for the Law of Crime Concentration. Journal of Quantitative Criminology. https://doi.org/10.1007/s10940-019-09404-1.

NUMBEO (2019). Crime Index 2019. https://www.numbeo.com/crime/rankings. jsp.

O'Brien, D. T. (2019). The action is everywhere, but greater at more localized spatial scales: Comparing concentrations of crime across addresses, streets, and neighborhoods. Journal of Research in Crime and Delinquency, 56(3), 339-377. https://doi.org/10.1177/0022427818806040.

O'Brien, D. T., \&Winship, C. (2017). The gains of greater granularity: The presence and persistence of problem properties in urban neighborhoods. Journal of Quantitative Criminology, 33(3), 649-674. https://doi. org/10.1007/s10940-016-9330-9.

Schnell, C., Braga, A. A., \& Piza, E. L. (2017). The influence of community areas, neighborhood clusters, and street segments on the spatial variability of violent crime in Chicago. Journal of Quantitative Criminology, 33(3), 469-496. https://doi.org/10.1007/s10940-016-9313-x.

Sidebottom, A., Kuo, T., Mori, T., Li, J., \& Farrell, G. (2018). The East Asian crime drop? Crime Science, 7(1), 6. https://doi.org/10.1186/s40163-018-0080-x.

Statistics Bureau in Japan (2018). Internal Migration in 2017. http://www.stat. go.jp/english/data/idou/2017np/index.html. Retrieved 24 Mar 2019.

Steenbeek, W., \& Weisburd, D. (2016). Where the action is in crime? An examination of variability of crime across different spatial units in The Hague, 2001-2009. Journal of Quantitative Criminology, 32(3), 449-469. https:// doi.org/10.1007/s10940-015-9276-3.

The Economist Intelligence Unit (2017). Safe cities index 2017: Security in a rapidly urbanizing world. https://dkf1ato8y5dsg.cloudfront.net/uploads/5/82/ safe-cities-index-eng-web.pdf.

Vandeviver, C., \& Steenbeek, W. (2019). The (in)stability of residential burglary patterns on street segments: The case of Antwerp, Belgium 2005-2016. Journal of Quantitative Criminology, 35(1), 111-133. https://doi. org/10.1007/s10940-017-9371-8.

Weisburd, D. (2015). The Law of Crime Concentration and the criminology of place. Criminology, 53(2), 133-157. https://doi.org/10.1111/17459125.12070.

\section{Publisher's Note}

Springer Nature remains neutral with regard to jurisdictional claims in published maps and institutional affiliations. 